\title{
The Impact of Combined (Aerobic-resistance) Training on Serum Levels of IGF-I and IGFBP-3 in Men with Prostate Cancer
}

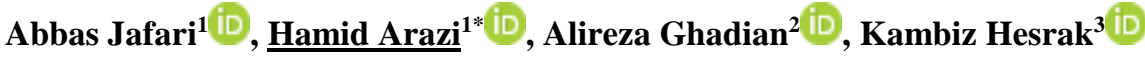 \\ 1. Dept. of Exercise Physiology, Faculty of Sport Sciences, University of Guilan, Rasht, Iran \\ 2. Dept. of Kidney and Urethral Cancers, Baqiyatallah Al-Azam Hospital, Tehran, Iran \\ 3. Dept. of Molecular Medicine, Baqiyatallah Al-Azam Hospital, Tehran, Iran
}

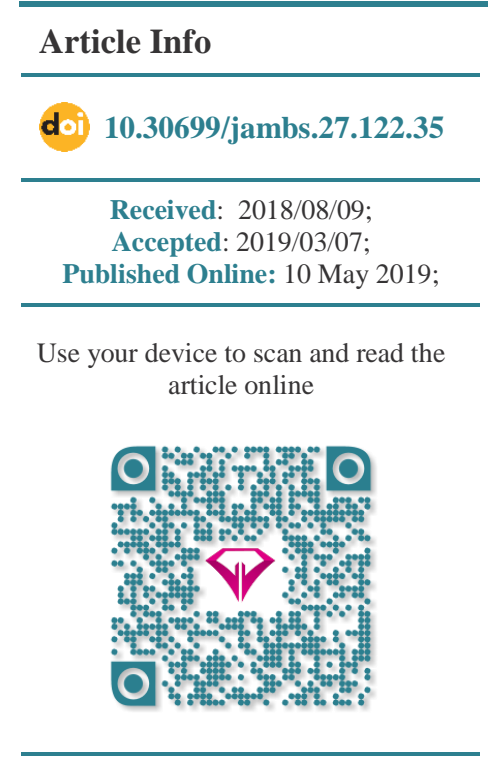

Corresponding Information: Hamid Arazi, Dept. of Exercise Physiology, Faculty of Sport Sciences, University of Guilan. Iran.

E-mail: hamidarazi@yahoo.com

\begin{abstract}
Background \& Objective: Prostate cancer is the most common cancer in men. The purpose of this study was to determine the effect of combined training (aerobicresistance) on serum levels of insulin-like growth factor-I (IGF-I) and insulin-like growth factor-binding proteins 3 (IGFBP-3) in men with prostate cancer.
\end{abstract}

Materials \& Methods: 20 eligible men with prostate cancer with an average age of $62.6 \pm 7.71$ years, height of $172.15 \pm 5.02 \mathrm{~cm}$, average weight of $75.6 \pm 11.6 \mathrm{~kg}$, and the body mass index $25.54 \pm 3.47$ were divided randomly into two groups (10 individuals each): the control and experimental groups. The experimental group experienced eight weeks of combined training (Aerobic resistance) with three sessions per week. During this period the control group did not participate in any exercise. At the beginning and the end of the period, $5 \mathrm{~mL}$ blood samples were taken to measure serum levels of IGFI and IGFBP-3. The obtained data were then analyzed using ANCOVA with P-value $\leq$ 0.05 .

Results: The results showed that the eight weeks of combined training significantly reduced the level of IGF-I in the experimental group $(P=0.001)$. Also, the combined training significantly increased the level of IGFBP-3 in the experimental group, which was significantly different from the control group $(P=0.036)$.

Conclusion: The results of this study indicate that the combined training can affect some of the factors associated with prostate cancer and may be able to contribute to the improvement of patients' disease (along with the main treatment protocol).

Keywords: Combined training, Prostate cancer, IGF-I, IGFBP-3

\section{Introduction}

Prostate cancer is the fourth most common cancer forms in the world and the most prevalent visceral cancer in men. Prostate cancer is the second cause of cancerrelated mortality in men older than 50 years of age after lung cancer (1). In developed countries, prostate cancer is the second common form of cancer, after skin cancer, and the most deadly cancer after lung cancer in men. One in every six men is affected by this condition (2). According to the American Society of Cancer, 565,469 American men have lost their lives because of prostate cancer in 2008 (3). Similarly, in Iran, prostate cancer is the third most common cancer in men $(9.4 \%$ of all cancers in men), after skin and gastric cancer (4). The increase in mortality and chemo/radiotherapy-related complications in developed forms of this cancer has given urgency in developing new methods of controlling prostate cancer. Cancer development in a long period, especially prostate cancer which is seen in middle-age and elderly population, shows a high rate of genetic and epigenetic changes for tumor growth (5). Insulin growth factors (IGF) are among these factors. IGF-1 is a trophic transmitter which acts by growth hormone and regulates metabolism as well as cell growth. There are six proteins which can bind with IGF (IGFBP-1 to HGFBP-6). According to previous studies, IGFBP-3 has the highest concentration and binding capacity to IGF-1 (6). IGFs are proteins which are produced by the liver in response to pituitary growth hormone. IGF has an important role in regulating cell proliferation, differentiation, apoptosis and transformation and acts as endocrine, autocrine and paracrine. Elevated levels of IGF-1 are associated with an increased risk of colon, prostate, and breast cancers (7). Lifestyle items such as diet and exercise have been shown to have the potential to reduce the risk of progression prostate cancer, although their mechanisms are unclear (8). The acute phase of exercise stimulates expression and release of IGF-1 from the liver. These polypeptides are responsible for the growth and development of somatic tissues such as skeletal muscle and bone through stimulation of superficial IGF-IR 
receptors. Insulin-like growth factor-1 (IGF-1) is a potential stimulating factor for natural cell growth and also has an anti opoptic effect on epithelial cells (9). Normal epithelial prostate cells have IGF-1 receptors and are dependent on IGF-1 for growth. In a variety of experimental studies, it has been shown that IGF-1 increases growth of both Androgen-dependent and independent cancerous cell lines (10). Regular physical activity increases insulin sensitivity and decreases insulin level at the same time. On the other hand, the effect of physical activity on decreasing IGF-1, free and total estradiol levels (11). IGF-1 is an important factor composed of a complex molecular network including growth hormone, insulin, IGF-2, IGF-BP, leptin, steroidal hormones and some cell receptors (5). IGF-1 is a hormone which stimulates growth by cell proliferation, and inhibition of apoptosis and its level is regulated by liver synthesis, growth hormone, and nutritional materials. IGF-1 regulates mitogenic and anti-apoptotic messages in various normal and cancerous cells; so, it can alter apoptosis. It also affects cancer-related molecules indirectly (12). IGFBPs transfer IGF from blood to the goal tissue and also regulate recycling of IGF as inhibitor, stimulator, carrier or reservoir of IGF (13).

There are six types of proteins binding to IGFs among which IGFBP-3 accounts for $80 \%$ of these proteins. The main role of IGFBP-3 is prolonging the half-life of IGF1 , and most of the recent studies has shown an inverse relation between IGFBP-3 and risk of prostate cancer. IGFBP-3 affects biological availability of IGF-1 and has a separate effect on PC-3 prostate cancer cell line (14). Regular physical activity decreases insulin and IGF-1 levels and increases IGFBP-1 and Sex Hormone Binding Globulin. Several epidemiological studies have reported that physical activity may decrease the risk of prostate cancer, but there are several controversies. There are not much data about the effect of exercise after a diagnosis of prostate cancer. It has been reported that a low-fat diet and regular exercise decrease the serum level of IGF-1. Also, serum IGFBP-3 may alter carcinogenicity of prostate cancer cells; although results have been controversial (15). Doing some types of exercise such as resistance and power is called combined exercise (16). Combined exercise is an effective way of reducing body fat percentage and improving body composition. Strength and endurance exercises increase functional abilities and health status by changing body composition. Since exercises combine both strength and endurance exercises, subjects will most likely benefit from both types of exercises (17).

In a study by Daniel Santa Mina et al. (2013), 26 men with prostate cancer under ADT protocol participated in an aerobic and resistance training for 24 weeks. The levels of IGF-1 after three months of resistance training significantly reduced, although this change was not lasting until the end of six months. In the resistance training group, the levels of IGFBP-3 showed a significant increase during six months compared to the baseline (8).
Thus, assessing the effect of different training with different patterns, especially concurrent training, on hormonal adaptation are of high importance. A few studies have reported the effect of combined training on levels of growth hormone, IGF-1, and IGFBP-3 in patients with cancer. So, the present study aimed to assess the impact of eight-week concurrent (aerobicresistance) training on plasma levels of IGF-1 and IGFBP-3 in men with prostate cancer.

\section{Materials and Methods}

This quasi-experimental study was conducted at Baqiyatallah university hospital between 2016 and 2017. The study protocol was registered at the ethics committee of Baqiyatallah University of Medical Sciences (Ref. No: IR.BMSU.REC.1395.17) and the Iranian Registry of Clinical Trials (IRCT20180 624040222N1). Three hundred and seventy men with prostate cancer were assessed for eligibility. Age between 50 and 75 years, not having any accompanying disease, the ability for quotidian activities and physical activity were considered as inclusion criteria. Patients with a history of smoking, hormone replacement therapy, physical activity, and training in the past six months were excluded from the study. These factors were assessed by the Physical Activity Readiness Questionnaire and medical history checklist.

After being informed of the study process and possible benefits and dangers of participation, patients signed an informed consent form. Patients were randomly allocated to two groups using a random number table: the first group underwent combined training and second group, as the control group didn't. Patients were instructed on physical activities program in one session. BMI, maximal oxygen uptake, hip and waist circumference, waist to hip ratio (WHR) and fat percentage of participants were measured 48 hours before and after the intervention. All anthropometric and blood tests were performed, forty-eight hours prior to the start of the first training session and 48 hours after the last training session. All the measurements were taken by a single person. Jackson and Pollock's formula was used for calculating body fat density (17). Using the modified Bruce test and the non-direct measurement method, the maximum oxygen consumption was calculated (18).

At first, individuals ran for 10 minutes on the treadmill. After conducting stretch movements, individuals started resistance training with $40 \%$ of estimated maximum strength. Movements were ordered as leg extension, leg curls, lat pull-down and chest press with a 90-second rest and gradual increase in resistance. The maximum tolerated resistance was considered as the repeated resistance for the person. Individuals were encouraged verbally for being motivated. The study individuals had a $5 \mathrm{~mL}$ of their blood sampled in Baqiyatallah Hospital laboratory for measuring IGF-1 and IGFBP-3 level (ng/mL) using 
ZellBio GmbH kit (catalog No: ZB-10103S-H9648, Germany) by ELISA method.

Individuals of case group started training in Ghadir sports complex, Tehran, Iran. From the day after sampling, case individuals trained three sessions per week for eight weeks based on instructions of American College of Sports Medicine (ACSM) and by researcher-designed aerobic/resistance training (19). Each session lasted between 60-80 minutes including warming up and cooling down exercises. Thirtyseconds of dynamic stretch movements, at least 10 minutes, 3 to 4 times, were performed as cooling down movements. The resistance training program included four exercises for upper and lower limbs muscles with 60 to $70 \%$ of one repetition maximum (1RM) for three times with ten repetitions and 2 to 3-minutes rest between sets. Aerobic training was started with a 15 minute activity with a severity of $60 \%$ of $\mathrm{VO}_{2 \max }$ for three sessions in a week (Tables 1 and 2). Control group were asked not to have any sports activities during the study period. No changes were made in diet or medications of study individuals. Exit criteria were set as: three or more session absences, participation in other sports exercises, injuries, use of supplements or medications without the permission of the physician. Two days after the last session of training, laboratory and anthropometric factors were measured again and compared to pre-intervention measures.

Data were analyzed using SPSS 21 (SPSS Inc., Chicago, IL. USA). Normal distributed variables (approved by 1-sample Kolmogorov-Smirnov test) were compared using One Way ANCOVA test between the groups. The paired sample T-test was used to examine the significant difference between the beginning and the end of the period in each group. Mean, and standard deviation (SD) were used for describing categorical variables. A p value of less than 0.05 was considered statistically significant.

\section{Results}

Mean level of IGF-1 was $6 \pm 1.04 \mathrm{ng} / \mathrm{mL}$ in control and $16.54 \pm 1.93 \mathrm{ng} / \mathrm{mL}$ in the training group before intervention. After the intervention, the control group had a mean IGF-1 level of $14.72 \pm 2.14 \mathrm{ng} / \mathrm{mL}$ while it was $12.15 \pm 1.94$ in training group. Analysis showed a significant decrease in IGF-1 level in the training group $(P=0.001, \underline{\text { Figure } 1)}$ and a significant increase in IGF-1 level in the control group after intervention $(P=0.001$, Figure 1). There was a significant difference between training and control group for IGF-1 level after intervention ( $P=0.001$, Figure 1 and Table 3) .

Mean level of IGFBP-3 was $2.79 \pm 0.74 \mathrm{ng} / \mathrm{mL}$ in control and $1.69 \pm 0.12 \mathrm{ng} / \mathrm{mL}$ in the training group before intervention. After the intervention, the control group had a mean IGFBP-3 level of $2.16 \pm 0.26 \mathrm{ng} / \mathrm{mL}$ while it was $5.34 \pm 1.38$ in training group. Analysis showed a significant increase in IGFBP-3 level in the training group $(P=0.001$, Figure 2). There was a significant difference between training and control group for IGFBP-3 level after intervention $(P=0.036$, Figure 2).

Table 1. The performed aerobic training program in the present study on men with Prostate Cancer

\begin{tabular}{cccc} 
Exercise & week & intensity & Number of sessions \\
\hline $15 \mathrm{~min}$ & $1-2$ & $60 \% \mathrm{VO}_{2 \max }$ & \\
\hline $20 \mathrm{~min}$ & $3-4$ & $65 \% \mathrm{VO}_{2 \max }$ & 3 sessions per week \\
\hline $25 \mathrm{~min}$ & $5-6$ & $70 \% \mathrm{VO}_{2 \max }$ & \\
\hline $30 \mathrm{~min}$ & $7-8$ & $75 \% \mathrm{VO}_{2 \max }$ & \\
\hline
\end{tabular}

Table 2. The performed resistance training program in the present study on men with Prostate Cancer

\begin{tabular}{|c|cccccc}
\hline Exercise & Number of sessions & week & Intensity & Reps & Sets & Rest \\
\hline Leg extension & & $1-2$ & $\% 601 \mathrm{RM}$ & 10 & \\
\hline Lat pull-down & 3 & $3-4$ & $\% 651 \mathrm{RM}$ & 10 & $2-3 \mathrm{~min}$ \\
\hline Chest press & & $5-6$ & $\% 701 \mathrm{RM}$ & 10 & 10 \\
\hline Leg curls & $7-8$ & $\% 751 \mathrm{RM}$ & 10 \\
\hline
\end{tabular}


Table 3. Results obtained from ANCOVA test for the between group comparisons for IGF-1 and IGFBP-3 Proteins

\begin{tabular}{cccccccc} 
& \multicolumn{2}{c}{ Training Group } & & \multicolumn{3}{c}{ Control Group } \\
Variable & $\begin{array}{c}\text { Pre-Test } \\
(\text { Mean } \pm \text { SD) }\end{array}$ & $\begin{array}{c}\text { Post Test } \\
(\text { Mean } \pm \text { SD) }\end{array}$ & $\begin{array}{c}\text { Pre-Test } \\
(\text { Mean } \pm \text { SD) }\end{array}$ & $\begin{array}{c}\text { Post Test } \\
\text { (Mean } \pm \text { SD) }\end{array}$ & $\begin{array}{c}\text { One-way } \\
\text { Anova }\end{array}$ & ES \\
IGF-1 & $16.54 \pm 1.93$ & $12.15 \pm 1.94$ & $6.00 \pm 1.04$ & $14.72 \pm 2.14$ & 0.001 & 0.505 \\
\hline IGFBP-3 & $1.69 \pm 0.12$ & $5.34 \pm 1.38$ & $2.9 \pm 0.74$ & $2.1 \pm 0.26$ & 0.036 & 0.235 \\
\hline
\end{tabular}

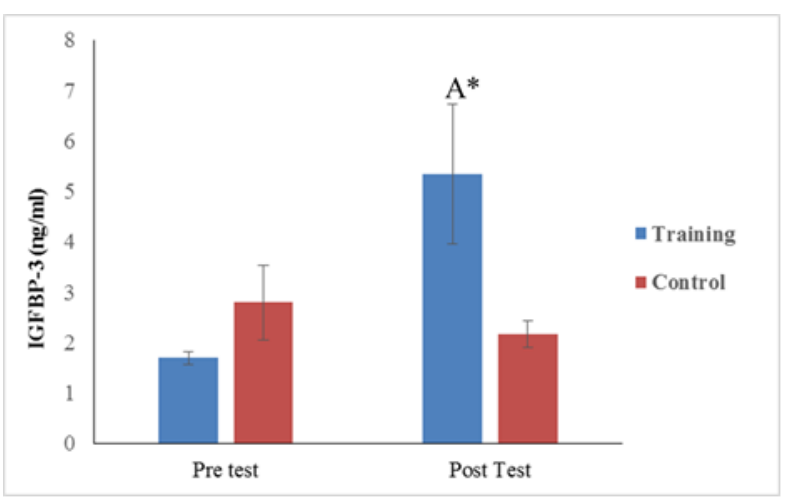

Figure 2. Serum level variation of IGFBP-3. The letter A Indicates a significant difference between the pre-test and post-test in the training group. The letter * Indicates a significant difference between the training group and the control group at the end of the trial.

\section{Discussion}

The results of this study indicate that an eight-week period of combined training (aerobic-resistance) are likely to affect some of the factors associated with prostate cancer which in turn may be able to contribute to the improvement of patients with prostate cancer (along with the main treatment protocol). We found that an eight-week period of combined training (aerobic-resistance) can significantly decrease the IGF1 level in the training group. On the other hand, Tofighi et al. (2012) found that an eight-week period of resistance training can decrease IGF-1 level more than resistance and combined training (20).

Seo et al. (2010) showed that combined and aerobic training might increase anabolic hormones like growth hormone and IGF-1 in senior women. They also argued that combined trainings was more effective on the secretion of anabolic hormones than aerobic trainings, which contradicts the results of this study (21). The variances may be attributable to differences in gender, training protocol or accuracy of measurement tools. Rosendal (2002) found that IGF-1 decreases in nontrained control individuals after 11 weeks of physical activity (22). Primary preparedness of individuals, training protocol, the severity of training and duration

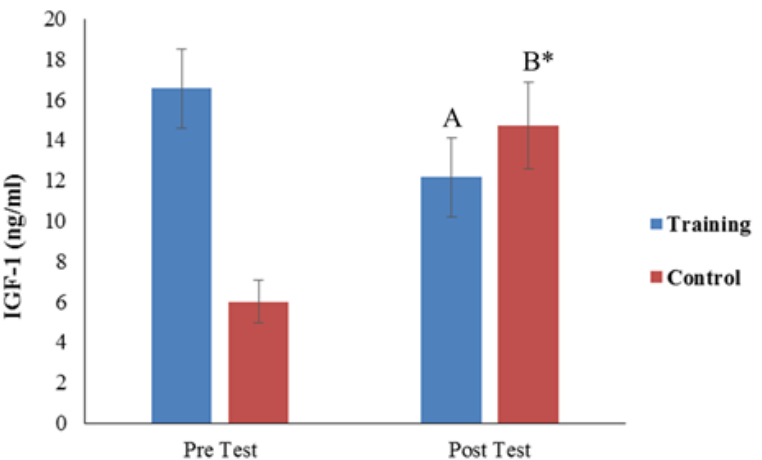

Figure 1. Serum level variation of IGF-1. The letter A Indicates a significant difference between the pre-test and posttest in the training group. The letter B indicates a significant difference between the pre-test and post-test in the control group. * Simply illustrates a meaningful difference between training and control groups at the end of the trial.

of rest may be reasons for the difference. It has been reported that physical activity, especially resistance training, may have effects on IGF axis proteins (23). Resistance training can increase IGF-1 level through increasing IGF-1 gene transcription; however, a direct relationship has been approved between BMI and IGF1 (23). Another possible mechanism is PI3K cascade which accelerates cell proliferation and mitosis and inhibits apoptosis. Cascade activity is dependent on insulin level, and physical activity decreased insulin level in case group; so, this decrease has resulted in inhibition or decrease in PI3K flow (24). IGF-1 stimulates phosphorylation of PI3K which itself activates phospholipid phosphatase. This enzyme inhibits apoptosis and results in cell proliferation (11).

Experimental studies have shown that high levels of IGF-1 are related to prostate cancer (5). Also, high levels of IGF-1 have been related to the risk of prostate cancer in three prospective studies (25). Regular physical activity may potentially postpone metastasis by changing IGF axis factors. Specialists believe that severe physical activity slows prostate cancer developments and decreases mortality (26). Tang et al. showed a significant decrease in the growth of LNCaP 
cells cultured in the serum of men under diet and physical activity interventions (27). They also reported that $\mathrm{LNCaP}$ cells growth decreased following the increase of IGFBP-1 and decrease of IGF-1 after training (27). Singh et al. (1999) showed that weight training in older adults increases muscle power and IGF-1 level (28). In Tung et al. (2002) study, an 11-day period of aerobic trainings decreased IGF-1 level as 60 ng and $170 \mathrm{ng}$ in a group which performed aerobic trainings for 14 years (27).

Biochemical studies have shown that IGFBP-3 is a long-lived half-life protein which is dependent on variations in metabolic pathways (29). Hence, it seems that only by applying some interfering factors (i.e. resistance activity) over a long period will cause tangible changes in the protein. Nindl, et al. (2001) Showed that applying a resistance activity for a long time by making changes in the pathways of metabolism would increase the production and release of IGFBP-3 immediately and in the recovery period after the resistance activity (30). It seems that the duration of the current research was suitable for resistance training, which has led to changes in the serum level of IGFBP3 in the experimental group.

Louigi et al. (2002) reported that IGFBP-3 was significantly increased after an increase in growth hormone following exercise (31). Recent studies have emphasized the role of IGFBP-3 in the prevention of IGF-1 breakdown and lowering of free IGF-1 level (31). Researchers have shown that individuals with congenital growth hormone deficiency and low levels of IGF-1 have lower risks of breast, prostate, colon, gastric, liver, pancreas, ovary, thyroid, brain and uterus cancers (32). Previous studies found that higher levels of IGF-1and low levels of IGFBP-3 increase risk of prostate cancer development (33). Khosravi et al. reported that the highest level of IGFBP-3 was found in healthy people followed by people with prostate cancer limited to prostate tissue; while the lowest IGFBP-3 level was in patients with prostate cancer bone metastasis (34).

\section{Conclusion}

The Findings of the present study showed that eight weeks of the combined training program in men with prostate cancer, significantly decreased their IGF-1 level. Also, IGFBP-3 level was significantly increased in the experimental group. It seems that using these training programs in a precise period maybe beneficial in prevention of prostate cancer development beside special treatment protocols. Several factors seem to be effective in research outcomes. Factors such as age, sex, race, overweight, stage of disease, type of exercises, training records and initial level of preparation, severity, and duration of exercises, and even psychological issues can affect the results. It is therefore recommended that these factors be considered in order to interpret and generalize the results. What is noteworthy is that most studies have stated the positive effects of exercise on related factors affecting diseases such as cancer. What is more important is to find out which exercises, along with the main treatment protocol, are appropriate and can improve the likelihood of recovery and ultimately improve the patient's quality of life. Answer to these questions will require further research in this regard.

\section{Acknowledgment}

We would like to thank the clinical research development unit of Baqiyatallah hospital for helping us with this research.

\section{Conflict of Interest}

The authors declared no conflicts of interest.

\section{Funding}

This research was partially supported by Baqiyatallah Al-Azam university of medical sciences in Tehran, Iran.

\section{References}

1. Lujan M, Paez A, Llanes L, Miravalles E, Berenguer A. Prostate-specific antigen density. Is there a role for this parameter when screening for prostate cancer? Prostate cancer and prostatic diseases. 2001; 4(3): 146. [DOI:10. 1038/sj.pcan.4500509] [PMID]

2. Siegel R, Naishadham D, Jemal A. Cancer statistics for hispanics/latinos, 2012. CA: a Cancer J Clin. 2012; 62(5): 283-98. [DOI:10.3322/caac.21153] [PMID]

3. Siegel R, Ma J, Zou Z, Jemal A. Cancer statistics, 2014. CA A Cancer J Clin. 2014; 64(1): 9-29. [DOI:10.3322/c aac.21208] [PMID]

4. Hosseini M, SeyedAlinaghi S, Mahmoudi M, McFarland W. A case-control study of risk factors for prostate cancer in Iran. Acta Med Iran. 2010; 48(1): 61.

5. Noori Daloia MR eVEMg, diagnosis, prevention and gene therapy in prostatic cancer: review article. Tehran Univ Med J. 2009; 67(1): 1-14.

6. Janssen J, Jacobs M, Derkx F, Weber R, van der Lely A-J, Lamberts S. Free and total insulin-like growth factor I (IGFI), IGF-binding protein-1 (IGFBP-1), and IGFBP-3 and their relationships to the presence of diabetic retinopathy and glomerular hyperfiltration in insulin-dependent diabetes mellitus. J Clin End Meta. 1997; 82(9): 2809-15. [DOI:10.1210/jc.82.9.2809] [PMID] 
7. Devin JL, Bolam KA, Jenkins DG, Skinner TL. The influence of exercise on the insulin-like growth factor axis in oncology: physiological basis, current and future perspectives. Cancer Epid Biom Prev. 2016; 25(2): 239-249. [DOI:10.1158/1055-9965.EPI-15-0406] [PMID]

8. Santa Mina D, Connor KM, Alibhai Sh, et al. Exercise effects on adipokines and the IGF axis in men with prostate cancer treated with androgen deprivation: A randomized study. Can Urol Assoc J. 2013; 7(11-12): E692-E698. [DOI:10.5489/cuaj.235] [PMID] [PMCID]

9. Maki RG. Small is beautiful: insulin-like growth factors and their role in growth, development, and cancer. J Clin Oncol. 2010; 28(33): 4985-95. [DOI:10.1200/JCO.2009.27.5040] [PMID] [PMCID]

10. Cohen P, Peehl DM, Lamson G, Rosenfeld RG. Insulin-like growth factors (IGFs), IGF receptors, and IGF-binding proteins in primary cultures of prostate epithelial cells. J Clin End Metab. 1991; 73(2): 401-7. [DOI:10.1210/jcem-73-2401] [PMID]

11. Hursting SD, Lavigne JA, Berrigan D, Perkins SN, Barrett JC. Calorie restriction, aging, and cancer prevention: mechanisms of action and applicability to humans. Ann Rev Med. 2003; 54(1): 131-52. [DOI:10.1146/annurev.med.5 4.101601.152156] [PMID]

12. Baglietto L, English DR, Hopper JL, Morris HA, Tilley WD, Giles GG. Circulating insulin-like growth factor-I and binding protein-3 and the risk of breast cancer. Cancer Epid Prev Biom. 2007; 16(4): 763-8. [DOI:10.1158/10559965.EPI-06-0960] [PMID]

13. Collett-Solberg PF, Cohen P. The role of the insulin-like growth factor binding proteins and the IGFBP proteases in modulating IGF action. End Metab Clin. 1996; 25(3): 591614. [DOI:10.1016/S0889-8529(05)70342-X]

14. Kurek R, Tunn UW, Eckart O, et al. The significance of serum levels of insulin-like growth factor-1 in patients with prostate cancer. Br J Urol Int. 2002; 85(1): 125-29. [DOI:10.1046/j.1464-410x.2000.00350.x] [PMID]

15. Renehan AG, Zwahlen M, Minder C, T O'Dwyer S, Shalet SM, Egger M. Insulin-like growth factor (IGF)-I, IGF binding protein-3, and cancer risk: systematic review and meta-regression analysis. Lancet. 2004; 363(9418): 134653. [DOI:10.1016/S0140-6736(04)16044-3]

16. Wall B, Galvao D, Fatehee N, et al. Exercise improves Vo2max and body composition in ADT-treated prostate cancer patients: 1240 Board\# 4 June 18 . Med Scie Sports Exerc. 2017; 49: 333-4. [DOI:10.1249/01.mss.000 0517784.17673.03]

17. Coburn JW, Malek MH. NSCA's Essentials of Personal Training 2nd Edition: Human Kinetics; 2012.

18. Schmitz KH, Courneya KS, Matthews C, et al. American College of Sports Medicine roundtable on exercise guidelines for cancer survivors. Med Scie Sports Exerc. 2010; 42(7): 1409-26. [DOI:10.1249/MSS.0b013 e3181e0c112] [PMID]

19. Tofighi A, Dehkordi AJ, Tartibian B, Shourabeh FF, Sinaei $M$. Effects of aerobic, resistance, and concurrent training on secretion of growth hormone and insulin-like growth factor1 in elderly women. J Isfahan Med School. 2012; 30(184).
20. Seo DI, Jun TW, Park KS, Chang H, So WY, Song W. 12 weeks of combined exercise is better than aerobic exercise for increasing growth hormone in middle-aged women. Int J Sport Nutr Exerc Metab. 2010; 20(1): 21-6. [DOI:10.11 23/ijsnem.20.1.21] [PMID]

21. Rosendal L, Langberg H, Flyvbjerg A, Frystyk J, Ørskov H, Kjær M. Physical capacity influences the response of insulin-like growth factor and its binding proteins to training. J Appl Phy. 2002; 93(5): 1669-75. [DOI:10.1152/jap plphysiol.00145.2002] [PMID]

22. Irwin ML, Varma K, Alvarez-Reeves M, et al. Randomized controlled trial of aerobic exercise on insulin and insulin-like growth factors in breast cancer survivors: the Yale Exercise and Survivorship study. Cancer Epid Prev Biom. 2009; 18(1): 306-13. [DOI:10.1158/1055-9965.EPI-08-0531] [PMID] [PMCID]

23. Schmitz KH, Ahmed RL, Hannan PJ, Yee D. Safety and efficacy of weight training in recent breast cancer survivors to alter body composition, insulin, and insulin-like growth factor axis proteins. Cancer Epid Prev Biom. 2005; 14(7): 1672-80. [DOI:10.1158/1055-9965.EPI-04-0736] [PMID]

24. Stattin Pr, Bylund A, Rinaldi S, et al. Plasma insulin-like growth factor-I, insulin-like growth factor-binding proteins, and prostate cancer risk: a prospective study. J Nati Cancer Ins. 2000; 92(23): 1910-7. [DOI:10.1093/jnci/92.23.1910] [PMID]

25. Giovannucci EL, Liu Y, Leitzmann MF, Stampfer MJ, Willett WC. A prospective study of physical activity and incident and fatal prostate cancer. Arch Int Med. 2005; 165(9): 1005-10. [DOI:10.1001/archinte.165.9.1005] [PMID]

26. Tung Ngo H, James Barnard R, Christopher N Tymchuk, Pinchas Cohen, William J Aronson. Effect of diet and exercise on serum insulin, IGF-I, and IGFBP-1 levels and growth of LNCaP cells in vitro (United States). Cancer Causes Control. 2002; 13: 929-935. [DOI:10.1023 /A:1021911517010] [PMID]

27. Singh MAF, Ding W, Manfredi TJ, et al. Insulin-like growth factor I in skeletal muscle after weight-lifting exercise in frail elders. Am J Phy Endocrinol Metab 1999; 277(1): E135E43. [DOI:10.1152/ajpendo.1999.277.1.E135] [PMID]

28. Bang P, Brandt J, Degerblad M, et al. Exercise-induced changes in insulin-like growth factors and their low molecular weight binding protein in healthy subjects and patients with growth hormone deficiency. Eur J Clin Investi. 1990; 20(3): 285-92. [DOI:10.1111/j.13652362.1990.tb01857.x] [PMID]

29. Nindl BC, Kraemer WJ, Marx JO, et al. Overnight responses of the circulating IGF-I system after acute, heavy-resistance exercise. J Appl Physiol. 2001; 90(4): 1319-26. [DOI:10.11 52/jappl.2001.90.4.1319] [PMID]

30. Di Luigi L, Guidetti L. IGF-I, IGFBP2, and-3: do they have a role in detecting rh GH abouse in trained men? Med Sci Sports exercise. 2002; 195: 1270-1278. [DOI:10.1097 100005768-200208000-00007] [PMID]

31. Orciari S, Di Nuzzo S, Lazzarini R, Caprari P, Procopio A, Catalano A. The effects of insulin and insulin-like growth factors on tumor vascularization: new insights of insulin-like growth factor family in cancer. Curr Medicinal Chem. 2009; 16(30): 3931-42. [DOI:10.2174/092986709789352268] [PMID] 
32. Kurek R, Tunn U, Eckart O, Aumüller G, Wong J, Renneberg $\mathrm{H}$. The significance of serum levels of insulinlike growth factor-1 in patients with prostate cancer. BJU Int. 2000; 85(1): 125-9. [DOI:10.1046/j.1464-410x.2000 .00350.x] [PMID]

\section{How to Cite This Article:}

Jafari A, Arazi H, Ghadian A, Hesrak K. The Impact of Combined (aerobic-resistance) Training on Serum Levels of IGF-I and IGFBP-3 in Men with Prostate Cancer. J Adv Med Biomed Res. 2019; 27 (122) :35-41

\section{Download citation:}

$\underline{\underline{B i b T e X}}|\underline{\underline{R I S}}| \underline{\text { EndNote }}|\underline{\underline{\text { Medlars }}}| \underline{\text { ProCite }}|\underline{\text { Reference Manager }}| \underline{\text { RefWorks }}$

\section{Send citation to:}

\$ Mendeley 2 Zotero RefWorks $\underline{\text { RefWorks }}$
33. Khosravi J, Diamandi A, Mistry J, Scorilas A. Insulin-like growth factor I (IGF-I) and IGF-binding protein-3 in benign prostatic hyperplasia and prostate cancer. J Clin End Metab. 2001; 86(2): 694-9. [DOI:10.1210/jcem.86.2.7211] [PMID] 